\title{
A Steroid Anesthetic Prolongs Inhibitory Postsynaptic Currents in Cultured Rat Hippocampal Neurons
}

\author{
Neil L. Harrison, Stefano Vicini, ${ }^{1}$ and Jeffery L. Barker \\ Laboratory of Neurophysiology, National Institute for Neurological and Communicative Disorders and Stroke, National \\ Institutes of Health, Bethesda, Maryland 20892, and 'FIDIA-Georgetown Institute for the Neurosciences, Washington, D.C. \\ 20007
}

\begin{abstract}
Whole-cell patch-clamp recordings were made from cultured rat hippocampal neurons to examine the effects of the steroidal general anesthetic alphaxalone (3 $\alpha$-hydroxy 5 $\alpha$-pregnane 11,20 -dione) on responses to pharmacologically applied and physiologically released GABA. At low micromolar concentrations in the anesthetic range, alphaxalone potentiated $\mathrm{Cl}^{-}$conductance responses elicited by GABA and also prolonged evoked GABA-mediated postsynaptic potentials. Under voltage clamp at $-\mathbf{4 0} \mathrm{mV}$, rapid outwardly directed synaptic currents were evoked that decayed with single exponential kinetics; mean decay time constant was $24 \mathrm{msec}$ at room temperature. Alphaxalone prolonged the decay of these inhibitory postsynaptic currents by 5- to 8-fold, with no increase in peak amplitude or change in growth time. This substantial prolongation of GABA-mediated inhibitory synaptic conductance at clinically effective concentrations may contribute significantly to the anesthetic activity of alphaxalone.
\end{abstract}

A link between the actions of some general anesthetics and synaptic inhibition has long been considered a possibility (Eccles et al., 1963), and studies of the anesthetic barbiturates have shown that these agents prolong IPSPs mediated by the amino acid transmitter GABA at a variety of central synapses (Nicoll et al., 1975; Scholfield, 1978; Weiss and Hablitz, 1984). Voltageclamp studies have shown that the time course of the synaptic current that underlies the IPSP is substantially prolonged by pentobarbitone with little, if any, change in amplitude (Collingridge et al., 1984; Segal and Barker, 1984b).

Recently, it has been suggested that the CNS depressant actions of the steroid anesthetic alphaxalone ( $3 \alpha$-hydroxy 5 $\alpha$-pregnane 11,20-dione) may also be mediated via enhancement of GABA-mediated inhibition. In guinea pig olfactory cortex (Scholfield, 1980), the time course of GABA-mcdiated inhibition is prolonged by alphaxalone. Alphaxalone has also been reported to prolong the duration of the dorsal root potential, which is thought to be mediated in part by GABA and which is associated with presynaptic inhibition of excitatory transmission from primary afferents to motoneurons (Lodge and Anis, 1984). It seems likely that these actions of the steroid anesthetic involve an interaction with GABA receptor-Cl

\footnotetext{
Received Apr. 10, 1986; revised July 17, 1986; accepted July 28, 1986.

We wish to thank Veronica Smallwood for cultured neurons and Jane Harrington for assistance with data analysis.

Correspondence should be addressed to Dr. N. L. Harrison at the above address. Copyright (c) 1987 Society for Neuroscience $0270-6474 / 87 / 020604-06 \$ 02.00 / 0$
}

channel complexes, since in pharmacological studies in rat cuneate slices alphaxalone potentiates responses to GABA but not glycine (Harrison and Simmonds, 1984). We have examined some of the details of alphaxalone's interactions with pharmacologically and physiologically activated responses to GABA in cultured embryonic rat hippocampal neurons using the wholecell recording technique. The results indicate that the steroid closely resembles pentobarbital in its effects on GABA-activated $\mathrm{Cl}^{-}$conductance but is effective at substantially lower concentrations.

\section{Materials and Methods}

Neurons from the embryonic rat hippocampus were grown in dissociated culture by methods previously described (Segal, 1983), and they were used in electrophysiological recordings after 2-4 weeks in culture.

Recordings were made at $22-24^{\circ} \mathrm{C}$ from 14 neurons having cell body diameters between 10 and $20 \mu \mathrm{m}$. Culture plates were placed on the modified stage of an inverted phase-contrast microscope. We used the patch-clamp technique to record whole-cell currents and potentials with the List EPC-7 amplifier (Hamill et al., 1981). Pipette-membrane seals of between 2 and $20 \mathrm{G} \Omega$ were obtained, following which the patch of membrane enclosed by the pipette was disrupted by suction (Fenwick et al., 1982). Resting membrane potentials were between -50 and -60 $\mathrm{mV}$ and cell input resistances between 100 and $300 \mathrm{M} \Omega$. Pipette resistance prior to seal formation was 3-5 M . Pipette current and voltage were sampled and digitized at various rates between 1 and $5 \mathrm{kHz}$ and stored for subsequent retrieval and analysis on a PDP 11/23 computer.

Patch pipettes were filled with a solution containing (in $\mathrm{MM}$ ): $\mathbf{K}$ gluconate, 145; $\mathrm{MgCl}_{2}, 2$; EGTA, 1.1; $\mathrm{CaCl}_{2}, 0.1$ (pCa 7.8); HEPES, 5, titrated to $\mathrm{pH} 7.2$ with $\mathrm{KOH}$. Sucrose was added to adjust the osmolarity to $315 \mathrm{mOsm}$. The extracellular solution contained (in $\mathrm{mM}$ ): $\mathrm{NaCl}, 135$; $\mathrm{KCl}, 5 ; \mathrm{CaCl}_{2}, 4 ; \mathrm{MgCl}_{2}, 8$; HEPES, 5, titrated to $\mathrm{pH} 7.4$ with $\mathrm{NaOH}$, $325 \mathrm{mOsm}$. The high concentration of $\mathbf{M g}^{2+}$ used in the extracellular medium resulted in a low level of "background" synaptic activity (Segal and Barker, 1984b), which enabled us to evoke single inhibitory events with a reproducible amplitude. The liquid junction potential between the 2 solutions was eliminated by placing the reference electrode in a side compartment containing the intracellular medium and connecting the 2 compartments with a low-resistance bridge. In a few experiments, $145 \mathrm{~mm} \mathrm{KCl}$ was substituted for $\mathrm{K}$ gluconate in the pipette solution.

Inhibitory postsynaptic potentials (IPSPs) and currents (IPSCs) were evoked in the recorded cell by stimulating another cell in the field by application of short ( $50-100 \mathrm{msec}$ ) pulses of $20 \mu \mathrm{M} \mathrm{L}$-glutamate, applied close to the cell body of the "presynaptic" neuron by pressure ejection from a micropipette (Segal and Barker, 1984b). In experiments in which GABA, bicuculline, and alphaxalone were applied to neurons under study, these substances were also ejected from micropipcttes positioncd within $20-30 \mu \mathrm{m}$ of the postsynaptic cell body. GABA and bicuculline were obtained from Sigma; alphaxalone and its $\beta$-hydroxy analog were kindly supplied by Dr. K. Child of Glaxo Ltd.

IPSC decay time constants and peak amplitudes for each cell in the presence and absence of alphaxalone were determined as the mean values of these 2 parameters over 5-50 individual IPSCs recorded at $-40 \mathrm{mV}$. Data are expressed as means \pm SEM. Charge transfer during 


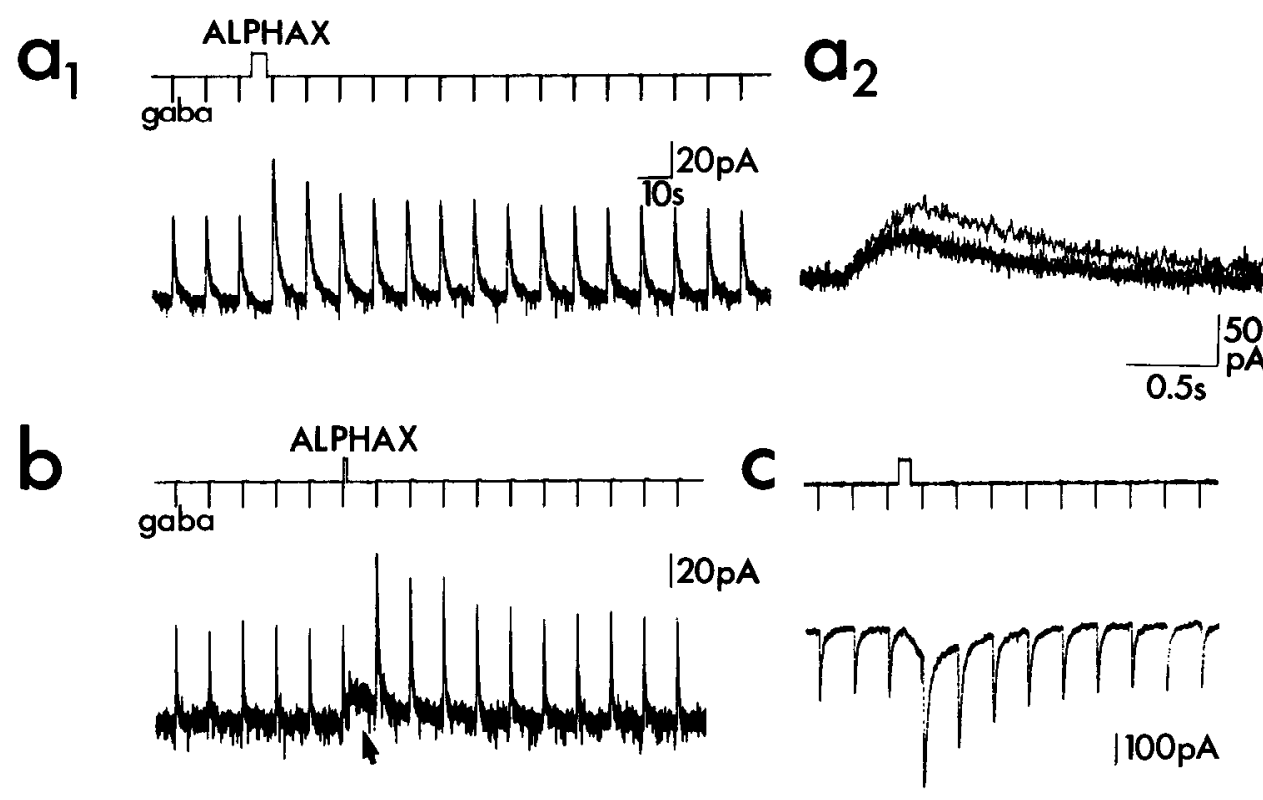

Figure 1. Alphaxalone potentiates GABA-evoked membrane currents. Voltage-clamp recordings from rat hippocampal neurons. $a$ and $b$, Recordings were made from neurons voltage-clamped at $-40 \mathrm{mV}$ with a patch pipette containing $145 \mathrm{~mm} \mathrm{~K}$ gluconate. GABA (10 $\mu \mathrm{M})$ was applied to the cell body of the neuron under study by pressure ( $<2 \mathrm{psi})$ in brief pulses $(50 \mathrm{msec}, 0.08 \mathrm{~Hz}$, as indicated by downward deflections) evoking transient outward currents. Alphaxalone was applied from a pipette containing either 1 or $10 \mu \mathrm{M}$ steroid (upward deflections). In $a, 1 \mu \mathrm{M}$ alphaxalone was applied; in $b, 10 \mu \mathrm{M}$ alphaxalone. $a 2$, Expanded traces of the current responses in $a 1 ; 3$ control responses are shown superimposed together with the first current response following alphaxalone application. Note that in $b$ the higher concentration of alphaxalone evokes a small outward current (arrow). $c$, Recording was made with a patch pipette containing $145 \mathrm{~mm} \mathrm{KCl}$ from a cell voltage-clamped at $-50 \mathrm{mV}$. Application of GABA under these recording conditions evoked inward current. Alphaxalone was applied from a pipette containing $1 \mu \mathrm{M}$ steroid. Under these conditions, alphaxalone application produced a small inward current.

individual IPSCs is equal to the integral of the synaptic current with respect to time and was determined from the area under the IPSC envelope by numerical integration (Gardner, 1980) using $600 \mu \mathrm{sec}$ intervals.

\section{Results}

\section{Alphaxalone increases $\mathrm{GABA}$-evoked $\mathrm{Cl}^{-}$current responses}

Previous work on alphaxalone has shown that the steroid anesthetic can increase the amplitude of GABA-evoked responses in the rat cuneate nucleus (Harrison and Simmonds, 1984) and in cultured rat spinal cord neurons (Barker et al., 1986). Before studying the effects of the anesthetic on inhibitory synaptic signals in rat hippocampal neurons, it was first necessary to demonstrate that the steroid altered responses to GABA in these neurons. In hippocampal neurons voltage-clamped at $-40 \mathrm{mV}$, application of brief pulses of GABA evoked small outward currents that reversed in polarity at membrane potentials close to $-60 \mathrm{mV}$. The ionic mechanism of these responses has been studied previously and established to involve activation of $\mathrm{Cl}^{-}$ conductance (Segal and Barker, 1984a). Alphaxalone (0.1-1 $\mu \mathrm{M}$ ) increased the peak amplitude of membrane current responses evoked by GABA (Fig. 1, al). GABA-evoked currents were not only increased in peak amplitude but also in duration (Fig. 1, a2). This effect was reversible within 1-2 min. When higher concentrations of alphaxalone (5-10 $\mu \mathrm{M}$ ) were applied, it was obvious that the anesthetic also evoked a slowly developing outward current (Fig. $1 b$, arrow) that decayed within a minute after terminating the application. This outward current response was routinely recorded in experiments in which alphaxalone was applied to the membrane in the absence of applied GABA.

When $\mathrm{KCl}$ was substituted for $\mathrm{K}$ gluconate in the pipette solution, GABA evoked inward current responses at a holding potential of $-50 \mathrm{mV}$, which were also potentiated by alphaxalone (Fig. 1c). Under these conditions, alphaxalone application was associated with an inwardly directed current that was also recorded in the absence of applied GABA.

\section{Inhibitory postsynaptic conductances are mediated by $G A B A$}

In order to detect IPSPs, we held the recorded cell at $-45 \mathrm{mV}$ in current-clamp. Under these conditions and with appropriate stimulation of other neurons in the field of the recorded cell, we evoked hyperpolarizing PSPs in the recorded cell. Hyperpolarizing PSPs typically had a complex nonexponential decay, lasting for 50-250 msec. They were significantly longer in duration in neurons having higher input resistance and reversed between -60 and $-70 \mathrm{mV}$ (Fig. $2 a$ ). The hyperpolarizing PSPs were blocked by somatic application to the recorded cell of bicuculline $(50 \mu \mathrm{M})$, a well-established antagonist of the inhibitory actions of GABA. These results strongly suggest that these IPSPs are mediated by GABA (Segal and Barker, 1984b).

After recording IPSPs under current-clamp conditions, cells were voltage-clamped at $-40 \mathrm{mV}$ to reveal the underlying outwardly directed IPSCs. These IPSCs were also depressed by bicuculline in a reversible manner and reversed in polarity at holding potentials between -60 and $-70 \mathrm{mV}$ (Fig. $2 b$ ). The evoked currents cxhibitcd a rapid growth phase (20-80\% of peak in 1-2 msec) and characteristically decayed as a single exponential whose time constant ranged from 12 to $35 \mathrm{msec}$, the average in 14 cells being $24 \pm 2 \mathrm{msec}$ at $-40 \mathrm{mV}$ (e.g., Fig. $2 c)$.

\section{Alphaxalone prolongs IPSPs and IPSCs}

Application of 1-10 $\mu \mathrm{M}$ alphaxalone to the neuron under study always prolonged the decay of IPSPs (Fig. $3 a$ ) and sometimes 
$\mathbf{a}$

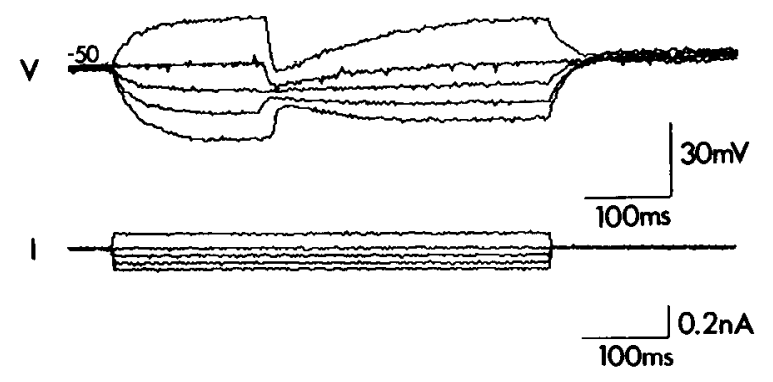

b

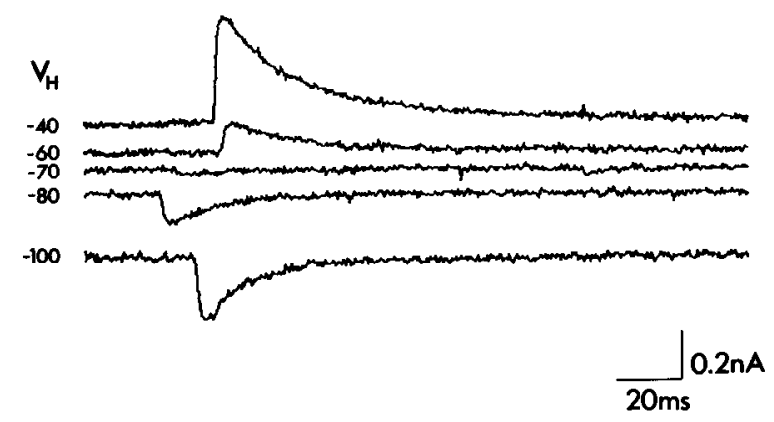

C
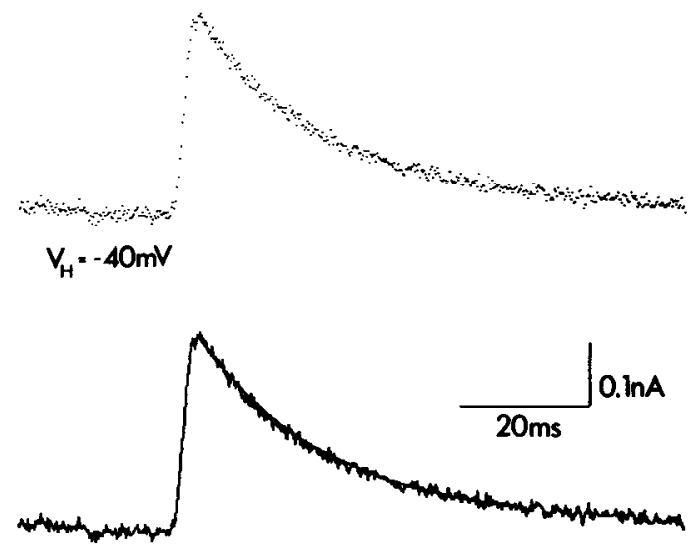

Figure 2. Properties of GABA-mediated inhibitory synaptic events in cultured rat hippocampal neurons. a, IPSPs evoked in 1 cultured rat hippocampal neuron by $50 \mathrm{msec}$ pressure application of L-glutamate to a presynaptic neuron. IPSPs were reversed by injection of hyperpolarizing current, in this case at a membrane potential close to $-60 \mathrm{mV}$. $h$, Inhibitory postsynaptic currents (IPSCs) recorded over a range of membrane potentials in another rat hippocampal neuron, illustrating the characteristic reversal potential between -60 and $-70 \mathrm{mV}$, and a decay time constant of 20-25 msec. $c$, Single IPSC, sampled at $5 \mathrm{kHz}$ at a holding potential of $-40 \mathrm{mV}$. The upper portion of the figure shows the individual data points sampled by the computer at $200 \mu \mathrm{sec}$ intervals, illustrating the rapid growth phase of the IPSC. The lower portion of the figure shows the same IPSC; the decay phase has been fitted with a single exponential with a time constant of $19.8 \mathrm{msec}$.

increased their peak amplitude. In view of the complex decay of IPSPs, we chose to study the interaction of alphaxalone with GABA-mediated synaptic events under voltage-clamp.

We investigated the effect of alphaxalone on the amplitude and decay time constant of IPSCs in 5 cells. In all 5 cells a 1 min application of $10 \mu \mathrm{M}$ alphaxalone produced a 3- to 10-fold prolongation of the exponential decay of IPSCs (Fig. $3 b$ ). This effect was extremely long-lasting, reversing slowly over a period of
10-20 min (Fig. 4). During this recovery period, IPSCs having a long decay time constant $(100 \mathrm{msec})$ exhibited a reversal potential indistinguishable from that of control IPSCs, indicating that the steroid anesthetic did not alter the reversal potential for GABA-mediated synaptic currents. The growth phase of IPSCs was unaffected by steroid application. Alphaxalone produced a modest depression of peak IPSC amplitude in all 5 cells (Table 1). By numerical integration of representative individual

\begin{tabular}{|c|c|c|c|c|c|c|}
\hline \multirow[b]{2}{*}{ Cell } & \multicolumn{2}{|c|}{$\begin{array}{l}\text { Decay time constant } \\
\text { (msec) }\end{array}$} & \multicolumn{2}{|c|}{$\begin{array}{l}\text { Peak amplitude } \\
\text { (pA) }\end{array}$} & \multicolumn{2}{|c|}{$\begin{array}{l}\text { Charge transfer } \\
\text { (pC) }\end{array}$} \\
\hline & Control & Alphaxalone & Control & Alphaxalone & Control & Alphaxalone \\
\hline 1 & 24 & 77 & 145 & 133 & 3.7 & 10.5 \\
\hline 2 & 20 & 68 & 500 & 418 & 10.9 & 29.1 \\
\hline 3 & 37 & 143 & 164 & 140 & 6.4 & 20.3 \\
\hline 4 & 34 & 253 & 285 & 190 & 9.2 & 48.4 \\
\hline 5 & 30 & 94 & 112 & 96 & 3.6 & 9.2 \\
\hline Mean & 28 & 121 & 241 & 195 & 6.7 & 23.5 \\
\hline
\end{tabular}

For decay time constant and peak amplitude, each control value represents the mean of measurements from the 10 IPSCs recorded immediately prior to the application of the steroid anesthetic. The values quoted for alphaxalone are the means of 3-5 IPSCs recorded during application of the anesthetic from a pressure pipette containing $10 \mu \mathrm{M}$ alphaxalone placed within $20-30 \mu \mathrm{m}$ of the postsynaptic cell body. Charge transfer was determined by numerical integration of a single representative IPSC in each case. 
a
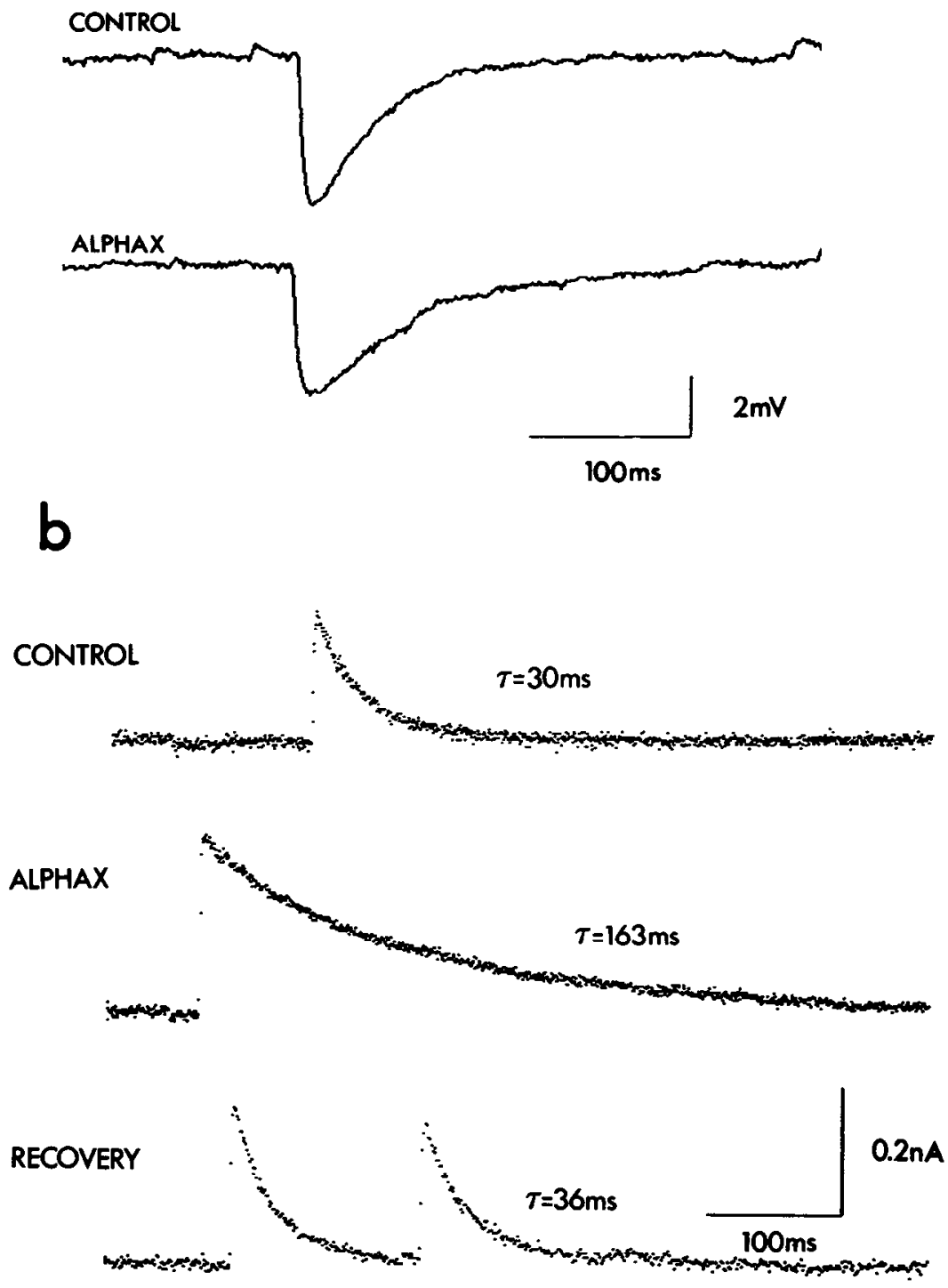

Figure 3. IPSP and IPSC durations are increased by alphaxalone. $a$, IPSPs recorded from the same neuron before and during the application of $1 \mu \mathrm{M}$ alphaxalone to the postsynaptic cell body. The IPSP decay phase is substantially prolonged in the presence of the anesthetic. $b$. IPSCs recorded from another neuron before, during, and after a $1 \mathrm{~min}$ application of $10 \mu \mathrm{M}$ alphaxalone to the recorded neuron. During the application of the anesthetic, the IPSC decay is still well fitted by a single exponential, but the decay time constant is increased over 5-fold. The IPSC decay showed almost complete recovery within 10-20 min after the drug application.

IPSCs, we were able to calculate the amount of charge transferred during a single IPSC in the presence and absence of alphaxalone. The results of this analysis showed that, even though alphaxalone slightly depressed IPSC peak amplitude, the net charge transfer was increased by between 3-and 5-fold in every cell (Table 1). In contrast to the potent action of alphaxalone on IPSCs, the corresponding $3 \beta$-hydroxy compound ("betaxalone") was completely without effect in 3 cells to which it was applied at a concentration of $10 \mu \mathrm{M}$.

\section{Discussion}

The potentiating action of alphaxalone on $\mathrm{Cl}^{-}$current responses to exogenous GABA in cultured rat hippocampal neurons is similar to that recorded in spinal cord neurons (Barker et al., 1986) and bovine chromaffin cells (Cottrell et al., 1986). At lower concentrations $(1 \mu \mathrm{M}$ in the pharmacological application pipette), alphaxalone potentiated $\mathrm{Cl}^{-}$conductance responses to GABA without any detectable effect on passive membrane properties. The amplitude and duration of responses to GABA were increased, as observed in cultured spinal neurons. Fluctuation analysis of GABA-evoked currents recorded in spinal neurons suggests that alphaxalone enhances such responses to GABA by increasing the mean open time of GABA-activated $\mathrm{Cl}^{-}$channels (Barker et al., 1986). Presumably, this mechanism also accounts for the enhancement by the steroid of macroscopic current responses to GABA in hippocampal neurons. In spinal cord neurons and bovine chromaffin cells, higher concentrations of alphaxalone evoked $\mathrm{Cl}^{-}$currents in the absence of applied $\mathrm{GABA}$, and these responses were depressed by the GABA antagonist bicucullinc (Barker et al., 1986; Cottrell et al., 1986), indicating that the steroid itself can activate $\mathrm{Cl}^{-}$conductance mechanisms associated with GABA receptors. Responses of the same type were observed in hippocampal neurons in the present experiments.

In addition to increasing the amplitude and duration of $\mathrm{Cl}^{-}$ conductance responses to exogenously applied GABA, alphaxalone had remarkable effects on the time course (but not the amplitude) of IPSPs and IPSCs recorded in hippocampal neu- 

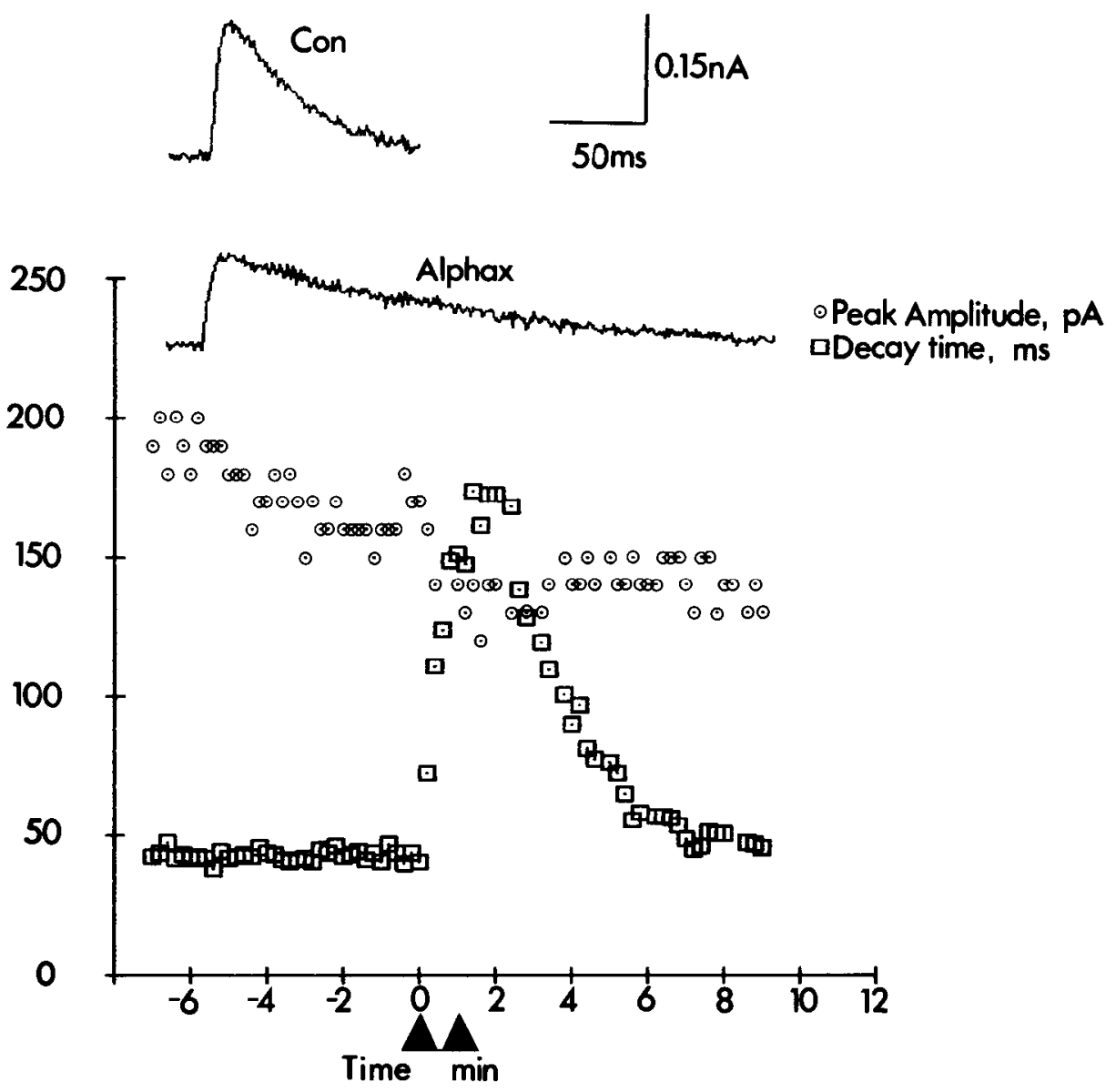

Figure 4. Time course of the effects of alphaxalone on IPSC decay time constant and peak amplitude. A $1 \mathrm{~min}$ application of alphaxalone was begun at time 0 (period of application indicated by arrow's). The steroid was applied by pressure from a pipette containing 10 $\mu \mathrm{M}$ alphaxalone placed within $20-30 \mu \mathrm{m}$ of the postsynaptic cell body. A large increase in the IPSC decay time constant was observed following steroid application that reversed within about $10 \mathrm{~min}$, while the peak IPSC amplitude was little affected by the application of alphaxalone. Inset curves show examples of the IPSCs before (control) and during application of alphaxalone to the cell.

rons, sometimes increasing the exponential decay time constant of the IPSC by a factor of 10. Previous studies of pentobarbital's effects on GABA-mediated IPSCs have demonstrated that the anesthetic barbiturate is capable of prolonging IPSC decay up to 8-fold (Collingridge et al., 1984; Segal and Barker, 1984b; Gage and Robertson, 1985), while the other class of established modulators of GABA-activated $\mathrm{Cl}^{-}$conductance, the benzodiazepines (e.g., diazepam), cause only a limited (up to 2-fold) increase in IPSC decay time constant (Segal and Barker, 1984b; S. Vicini and N. L. Harrison, unpublished observations). Like pentobarbital, alphaxalone did not increase the amplitude of the IPSC (Segal and Barker, 1984b; Gage and Robertson, 1985) but at higher drug concentrations often caused a small reduction in IPSC amplitude.

Previous investigators have shown that the prolongation of IPSC decay by pentobarbital is unlikely to be due to drug interference with GABA uptake mechanisms: Pentobarbital does not alter GABA uptake in vitro (Jessell and Richards, 1977), and large doses of the GABA uptake inhibitor nipecotic acid fail to prolong the decay of IPSCs in rat hippocampal slices (Gage and Robertson, 1985). It therefore appears that GABA reuptake does not normally determine the duration of IPSC decay. It seems more likely that the IPSC decays exponentially as a result of the probabilistic isomerization of subsynaptic GABA receptor-ion channel molecules following transient activation by synaptically released transmitter. Such an explanation is supported by the observation that the IPSC decay time constant closely approximates the mean channel open time estimated by fluctuation analysis of currents evoked by exogenous GABA.
Fluctuation analysis also indicates that the effective mean open time of GABA-activated channels is increased by pentobarbital (Study and Barker, 1981; Segal and Barker, 1984b). Thus, the most parsimonious explanation of pentobarbital's effect on IPSC decay is that the drug binds postsynaptically in the region of the GABA receptor- $\mathrm{Cl}^{-}$ion channel complex and stabilizes the channel in the "open," or conducting, conformation (Segal and Barker, 1984b; Gage and Robertson, 1985). The results described above, together with the observation that alphaxalone prolongs the mean open time of GABA-activated $\mathrm{Cl}^{-}$channels as determined by fluctuation analysis (Barker et al., 1986), strongly suggest that alphaxalone binds to a site close to, or identical with, that at which pentobarbital interacts with the receptor-channel complex to produce a similar prolongation of the open time of $\mathrm{Cl}^{-}$channels activated by synaptically released GABA. The steroidal anesthetic appears to be between 20-50 times more potent than pentobarbital, since bath application of $200 \mu \mathrm{M}$ pentobarbital produced about the same increase in IPSC decay time constant (Gage and Robertson, 1985) as did application of $10 \mu \mathrm{M}$ alphaxalone in the present study.

Several pieces of cvidence indicate the likcly relevance of these actions of the steroid in mediating its CNS depressant actions. First, the steroid concentrations used in the present study are in the $1-10 \mu \mathrm{M}$ range, as are the plasma concentrations of alphaxalone measured during surgical anesthesia in man (Sear and Prys-Roberts, 1979). Second, in our experiments, $3 \beta$-hydroxy $5 \alpha$-pregnane 11,20-dione, which completely lacks anesthetic activity, was without effect on the IPSC. Finally, we have recently discovered that certain metabolites of steroid hor- 
mones also enhance $\mathrm{Cl}^{-}$conductance responses to $\mathrm{GABA}$ at concentrations between $100 \mathrm{nM}$ and $1 \mu \mathrm{M}$; the most potent of these metabolites are those that bear a striking structural similarity to alphaxalone (Barker et al., 1986; Majewska et al., 1986). These steroid hormone metabolites also possess marked CNS depressant activity (Gyermek et al., 1968), for which no plausible explanation has been apparent until now.

In summary, we have found that the steroid anesthetic alphaxalone produces a striking prolongation of the GABA-mediated inhibitory postsynaptic conductance in cultured rat hippocampal neurons. The steroid closely resembles pentobarbital in its actions on GABA-mediated IPSCs and IPSPs. These actions would be expected to prolong the period in which the probability of action potential generation by the recipient cell is decreased, and thus to increase the effectiveness of GABAmediated synaptic inhibition in the mammalian CNS, and may play an important role in the induction of the anesthetic state by these 2 compounds.

\section{References}

Barker, J. L., N. L. Harrison, G. D. Lange, M. D. Majewska, and D. G. Owen (1986) Voltage-clamp studies of the potentiation of GABAactivated chloride conductance by the steroid anaesthetic alphaxalone and a reduced metabolite of progesterone in cultured rat C.N.S. neurones. J. Physiol. (Lond.) 377: 83P.

Collingridge, G. L., P. W. Gage, and B. Robertson (1984) Inhibitory postsynaptic currents in rat hippocampal CA1 ncuroncs. J. Physiol. (Lond.) 356: 551-564.

Cottrell, G., J. J. Lambert, and J. A. Peters (1986) Alphaxalone potentiates GABA and stimulates the GABA receptor of bovine chromaffin cells. J. Physiol. (Lond.) 372: 48P.

Eccles, J. C., R. F. Schmidt, and W. D. Willis (1963) Pharmacological studies on presynaptic inhibition. J. Physiol. (Lond.) 168: 500-530.

Fenwick, E. M., A. Marty, and E. Neher (1982) A patch-clamp study of bovine chromaffin cells and their sensitivity to acetylcholine. J. Physiol. (Lond.) 331: 577-597.

Gage, P. W., and B. Robertson (1985) Prolongation of inhibitory postsynaptic currents by pentobarbitone, halothane and ketamine in CA1 pyramidal cells in rat hippocampus. Br. J. Pharmacol. 85: 675681.

Gardner, D. (1980) Time integral of synaptic conductance. J. Physiol. (Lond.) 304: 181-191.
Gyermek, L., J. Iriarte, and P. Crabbe (1968) Structure-activity of some steroidal hypnotic agents. J. Med. Chem. 11:117-125.

Hamill, O. P., A. Marty, E. Neher, B. Sakmann, and F. J. Sigworth (1981) Improved patch-clamp techniques for high-resolution current recording from cells and cell-free membrane patches. Pfluegers Arch. 391: $85-100$.

Harrison, N. L., and M. A. Simmonds (1984) Modulation of the GABA receptor complex by a steroid anaesthetic. Brain Res. 323: 287-292.

Jessell, T. M., and C. D. Richards (1977) Barbiturate potentiation of hippocampal i.p.s.ps is not mediated by blockade of GABA uptake. J. Physiol. (Lond.) 269: 42P.

Lodge, D., and N. A. Anis (1984) Effects of ketamine and three other anaesthetics on spinal reflexes and inhibitions in the cat. Br. J. Anaesth. 56: 1143-1151.

Majewska, M. D., N. L. Harrison, R. D. Schwartz, J. L. Barker, and S. M. Paul (1986) Steroid hormone metabolites are barbiturate-like modulators of the $\gamma$-aminobutyric acid receptor. Science 232: 1004 1007.

Nicoll, R. A., J. C. Eccles, T. Oshima, and F. Rubia (1975) Prolongation of hippocampal inhibitory postsynaptic potentials by barbiturates. Nature 258: 625-627.

Scholfield, C. N. (1978) $\Lambda$ barbiturate induced intensification of the inhibitory potential in slices of guinea pig olfactory cortex. J. Physiol. (Lond.) 275: 559-566.

Scholfield, C. N. (1980) Potentiation of inhibition by general anaesthetics in neurones of the olfactory cortex in vitro. Pfluegers Arch. 383: 249-255.

Sear, J. W., and C. Prys-Roberts (1979) Plasma concentrations of alphaxalone during continuous infusion with Althesin. Br. J. Anaesth. 51: 861-865.

Segal, M. (1983) Rat hippocampal neurons in culture: Responses to electrical and chemical stimuli. J. Neurophysiol. 50: 1249-1264.

Segal, M., and J. L. Barker (1984a) Rat hippocampal neurons in culture: Properties of GABA-activated $\mathrm{Cl}^{-}$ion conductance. J. Neurophysiol. 51: 500-515.

Segal, M., and J. L. Barker (1984b) Rat hippocampal neurons in culture: Voltage clamp analysis of inhibitory synaptic connections. J. Neurophysiol. 52: 469-487.

Study, R. E., and J. L. Barker (1981) Diazepam and (-)pentobarbital: Fluctuation analysis reveals different mechanisms for potentiation of GABA responses in cultured central neurons. Proc. Natl. Acad. Sci. USA 78: 7180-7184.

Weiss, D. S., and J. J. Hablitz (1984) Interaction of penicillin and pentobarbital with inhibitory synaptic mechanisms in neocortex. Cell. \& Mol. Neurobiol. 4: 301-317. 